\title{
Ménière's disease and biographical disruption: where family transitions
}

\section{collide}

\section{Sarah L. Bell ${ }^{a}$, Jessica Tyrrell ${ }^{b}$, Cassandra Phoenix . $^{\text {. }}$}

${ }^{a}$ Corresponding Author: European Centre for Environment and Human Health, University of Exeter Medical School, Knowledge Spa, Truro, Treliske, TR1 3HD, United Kingdom Email address: Sarah.Bell@exeter.ac.uk

b European Centre for Environment and Human Health, University of Exeter Medical School, Knowledge Spa, Truro, Treliske, TR1 3HD, United Kingdom Email: J.Tyrrell@exeter.ac.uk

${ }^{\mathrm{c}}$ Department for Health, University of Bath, Bath, BA2 7AY, United Kingdom Email address: C.Phoenix@bath.ac.uk

Abstract: People's lived experiences of chronic illness have garnered increasing research interest over the last 30-40 years, with studies recognising the disruptive influence of illness onset and progression, both to people's everyday lives and to their biographical selves. We extend this body of work, drawing on the experiences of people living with Ménière's disease; a long-term progressive vestibular disorder characterised by unpredictable episodes of debilitating vertigo, tinnitus and permanent sensorineural hearing loss. In response to calls for more critical examination of the wider biographical contexts in which chronic illnesses are encountered, we draw on 28 in-depth narrative interviews with Ménière's patients and their family members to discuss how personal chronic illness experiences may be closely entwined with, and deeply shaped by, the life transitions (illness-related and otherwise) of 'linked others'. Interviews were conducted in south west England from January to June 2015. Focusing on intersecting transitions of parenthood, caregiving and retirement, we explore how and why familial relationships can both facilitate and hinder adaptation to a lifetime of chronically disrupted normalities, contributing to fluctuating experiences of 'cherished time', 
'anomalous time' and 'turbulent time'. In so doing, we suggest that the onset and progression of chronic illness could usefully be re-conceptualised as one of many 'biographical oscillations' encountered during the life course that serve to re-route us between continually shifting life trajectories. In recognising life's dynamism and challenging the identity-limiting and self-damaging nature of entrenched cultural life course constructions, we suggest value in recognising alternative ways of 'living well' when negotiating the wide-ranging biographical maps that life can follow.

Keywords: England, Ménière's disease, chronic illness, lived experience, relationships, biographical disruption, narrative inquiry

\section{Introduction}

People's lived experiences of chronic illness have gained increasing research attention over the last 30-40 years, with studies emphasising the disruptive influence of illness onset and progression, both to people's everyday lives and to their biographical selves (Bury, 1982; Charmaz, 1995; Locock et al., 2009). Illness can throw well-practised routines and long-standing conceptions of the body-self into question (Lindsay, 2009), asking people to re-map their lives in ways that were rarely anticipated prior to illness onset.

This paper contributes to the growing literature on the debilitating impact of chronic illness onset and progression on people's lives, with a particular focus on the influence of intertwined life transitions on people's lived experiences of Ménière's disease; an idiopathic, progressive vestibular disorder. With a prevalence of approximately $0.25 \%$ (in the United Kingdom), and symptoms including severe vertigo, tinnitus and sensorineural hearing loss, Ménière's is experienced as a distressing and unpredictable condition (Kirby and Yardley, 2008), with sufferers reporting regular and long-lasting episodes of depression (Tyrrell et al., 2015). Much of the existing research on the 
links between Ménière's disease and mental health focuses on ill health prevalence, factors affecting quality of life (Yardley et al., 2003), and patient perceptions of symptom triggers (Kirby and Yardley, 2012). Few studies, however, have contextualised people's subjective experiences in the context of their everyday or whole lives, or examined how the timing of illness onset and progression influences their understanding and management of symptoms. As such, we know little about how one's life trajectory and sense of self may shape individual perceptions and experiences of Ménière's disease over time.

In this paper, we present the findings of an in-depth narrative study to explore how the intersection of illness progression with specific life transitions (personal and shared) can compound an embodied sense of suffering and loss of self for people trying to adjust to life with Ménière's. To do so, we draw on concepts of 'biographical disruption', 'ontological security' and 'linked lives'.

\section{Theoretical backdrop}

\section{Biographical disruption}

A prominent idea underpinning much of the work on chronic illness to date is Bury's (1982) theory of 'biographical disruption'. This suggests that experiences of chronic illness undermine the 'structures of everyday life and the forms of knowledge which underpin them' (1982: 169), thereby disrupting a person's biography, self-concept and envisaged future selves. Closely aligned with this work, Charmaz (1983: 168) suggests that progressive functional and social losses with chronic illness can catalyse a 'crumbling away' of former self-images, whilst also undermining opportunities to develop equally valued alternatives. The concept of biographical disruption has been applied to people's experiences of a multitude of acute and chronic conditions, including rheumatoid arthritis, sensory impairment, multiple sclerosis, stroke and cancer (for example, Dyck, 1995; Leveälahti et al., 2007; Roberts and Clarke, 2009; Grassman et al., 2012; Hannum and Rubinstein, 2016). 
Although biographical research has been disregarded by some as misconceived - Bourdieu's (2000) so-called 'biographical illusion' - it remains a powerful tool for understanding the multifaceted perceptions and interpretations that people have of their lives, the salience of different cultural norms in shaping how people 'aspire' and 'learn' to be in the world, and the ways in which this changes over time (Šikić-Mićanović, 2013). Biographies may not be linear or coherent, particularly in the face of unpredictable and relentless episodes of acute or chronic illness (Frank, 1995). However, there is value in understanding how and why people use and construct particular narratives or life stories to find meaning, strength and a sense of coherence through such experiences (Denzin, 1989; Depkat, 2014).

Calls have recently been made for greater consideration of the wider biographical contexts in which illnesses are encountered. As noted by Williams (2000), experiences of illness and the meanings attributed to them are deeply shaped by personal and structural economic, social and cultural contexts. Building on this, researchers have argued that disruption is not an inevitable consequence of chronic illness; it may be anticipated by those who have, for example, engaged in 'risky' lifestyle choices (Llewellyn et al., 2014), experienced multiple morbidity in later life (Faircloth et al., 2004), or endured lifelong personal, social and/or economic hardship (Sinding and Wiernikowski, 2008). This work has resulted in notions of 'biographical continuity' and 'biographical flow', whereby illness is thought to reinforce aspects of biography, weaving into the 'normal chaos' of everyday life (Llewellyn et al., 2014: 55).

Cautions have been raised in making assumptions of continuity, however, with researchers suggesting that even the lives of those dominated by illness and hardship can be deeply disrupted by illness progression (Sinding and Wiernikowski, 2008). Drawing on a longitudinal study with visually impaired individuals, Larsson and Grassman (2012: 1157) demonstrate how the lives of those born with impairment (or those encountering its onset from a young age) are 'shifting, disruptive, discontinuous to varying degrees, rather than continuous'. Such individuals are thought to live with 
double timetables or 'body tables'; whilst they are aware that critical complications or further losses are likely to occur, the actual onset of such losses can still feel premature or 'off time'. In this way, losses may be unexpected, feared and anticipated at the same time. Reeve et al. (2010) explain how an accumulation of disruptive events can hinder adaptation to lives characterised by ever more 'dynamic normalities'. Whilst people may feel equipped to deal with familiar illness, they can be overwhelmed by the onset of new unpredictable forms or stages of illness, struggling to continually 'recast' their biographies and re-choreograph everyday routines in the face of uncontrollable symptom manifestations and trajectories (Lindsay, 2009; Richardson et al., 2006).

\section{Narrative reconstruction and ontological security}

In the face of chronic illness, affected individuals may engage in processes of 'narrative reconstruction', seeking to re-story their lives to account for the illness experience. They try to 'establish points of reference between the (changed) body, self and society, reconstructing the past so that it has meaning or purpose for the present' (Sanderson et al., 2011: 619). This process may be continuous, with people forced to embrace a new 'dynamic normality' (Locock et al., 2009). For those who struggle to find coherence or bring biographical order to their illness experiences in this way, 'biographical limbo' (Lindsay, 2009) or 'chaos narratives' (Frank, 1995) may ensue. As noted by Nettleton et al. (2005), these can be the hardest narratives to listen to as they foreground the limits to modern medicine and the inherently fragile nature of the human condition. In so doing, they challenge people's basic need for 'ontological security'; a state achieved when one feels rooted, stable and 'whole' within a socially and materially predictable world (Giddens, 1991). Central to this state is the need for confidence in the continuity of one's self identity, a sense of agency in being able to withstand and adapt to change, and embedment in a 'cocoon' of trust relations acting as a buffer to everyday risks and associated anxieties (Croft, 2012). In the context of the biographical 'fracturing' (and, in the case of Ménière's, marked sensory and perceived material changes) 
occurring with chronic illness, the need for continuity in social relations becomes ever more pertinent (as touched on by Danermark and Möller, 2008).

\section{'Linked lives' and social relations}

The shared nature of people's illness trajectories - and the potential for personal disruptions to intersect with those of partners, close family and friends - has received somewhat less attention to date in the work on biographical disruption (Monaghan and Gabe, 2015). Yet, as noted by Grenier (2012: 128), life transitions often take the form of 'linked experiences that occur in relationships with the self, family, society', and these social relations may influence one's sense of stability whilst negotiating an increasingly unpredictable body. As such, personal chronic illness experiences may be closely entwined and shaped by the life transitions (illness-related or otherwise) of 'linked others'. This can enhance awareness of the fragile architecture of each other's lives, encouraging shared navigation of alternative ways of being in the world, and mutual adaptation to a 'shifted normality of doing things differently' (Davidson and Henderson, 2010: 464).

In this paper, we draw on patient experiences of Ménière's disease to examine how the intersection of illness progression with specific life transitions (shared by 'linked others') can intensify experiences of biographical disruption and ontological insecurity for people with longstanding Ménière's. In so doing, we respond to calls to extend the concept of biographical disruption to understand the influence of shifting family relationships and repeated transitions on people's lived experiences of chronic illness over time (Gregory, 2005; Larsson and Grassman, 2012). We focus on three significant transitions - parenthood, familial illness, and early retirement - to explore how and when close relationships facilitate and/or hinder adaptation to a lifetime of 'disrupted' or fluctuating normalities and how this, in turn, impacts upon these relationships. 


\section{Methods}

This paper draws on the findings of a wider study exploring the lived experiences - and perceived mental health impacts - of Ménière's disease in the context of people's everyday lives (Phoenix et al., 2015; Bell, in press). Adopting an in-depth qualitative approach, a purposive sample (Patton, 1990) of 20 Ménière's patients was recruited to take part in a detailed narrative interview, using open questioning and active listening techniques to explore with each participant: how they experience and seek to manage the condition in their day-to-day lives (medically, socially, emotionally and otherwise); efforts to understand and make sense of the condition in the context of their wider biographies; and the perceived impacts of its diverse and fluctuating symptoms on their emotional, social and physical health and wellbeing.

Participants were recruited from across the south west of England with assistance from the Ménière's Society (via their quarterly 'Spin' magazine and through relevant social media), and via snowballing. The sample (see Table 1) aimed to capture people at different stages of the condition, each having experienced symptoms in one or both ears (vertigo, tinnitus, aural fullness, distorted hearing) within the previous year. Aware of the challenges of diagnosing Ménières, we recruited only those individuals who had been formally diagnosed by an Ear Nose and Throat consultant (including 4 male, 16 female; aged between 30 and 75). Although the participants were mostly female, the condition is known to affect approximately twice as many women than men (Tyrrell et al., 2015). Most participants had been diagnosed between the ages of 40 and 60 (reflecting the classical age of Ménière's diagnosis), but three were diagnosed earlier (between the ages of 17 and 30) and two later (between the ages of 60 and 70). During four of the interviews, spouses were present (based on participant preference), and a further eight interviews were conducted with people identified by participants as integral to their management of the condition; in this study, these were all partners/spouses, although participants also discussed the importance of wider familial support networks. These interviews offered deeper insights into the shared impacts of 
Ménière's and the perceived importance of providing and receiving social support in managing the condition.

[Insert Table 1 here]

Ethical approval was secured for the study from the University of Exeter Medical School Research Ethics Committee (Approval Reference 13/09/029). Key ethical considerations included: ensuring informed participant consent prior to taking part and emphasising the option to withdraw at any time; maintaining participant confidentiality and anonymity throughout; designing participant-centred research, catering for potential vulnerabilities (illness related and otherwise) and prioritising participant comfort and safety, flexible scheduling, and welcoming of friends and family during the research if requested.

All interviews were undertaken from January to June 2015 at a time and place of participants' choosing, each lasting between 1 and 3.5 hours. Interviews were digitally recorded and transcribed verbatim (using pseudonyms to protect participant anonymity). Participants were sent a copy of their anonymised transcript upon completion for member-checking purposes (Tracy, 2010); although two participants sent additional details by email after reading their transcripts (regarding further medical interactions that had occurred since the interviews), none of the participants disagreed with the transcript content. Following a period of data immersion - listening back to recordings, reading and re-reading transcripts and noting down emerging themes - the transcripts and an initial coding framework were uploaded to NVivo 10 (qualitative data management software). The data were then subject to in-depth thematic narrative analysis (Riessman, 2008), expanding on the initial coding framework in order to capture evolving and more nuanced themes identified within the transcripts. Care was taken to note down where different themes appeared within each participant's life story and to ascertain how different life stages and trajectories shaped their experiences, expectations and self-management of Ménière's (Phoenix et al., 2010). 
Emerging findings were discussed with members of a Ménière's support group in August 2015, exploring the resonance of the data interpretations with their personal understandings, illness experiences and perceptions. Although the outcome of this may have been different with individuals who choose not to engage with support groups, those present were able to relate to the diversity of participant experiences discussed, including those emerging from the accounts of the eight study participants who were not recruited via (or part of) physical or online support groups. This process coupled with the themes emerging during the data analysis phase - underlined the importance of understanding the intersection of participants' personal illness trajectories with wider familial transitions in order to identify phases in the life course when additional support (medical, psychological and social) would be of particular value to patients and their families, helping to minimise adverse mental health outcomes.

\section{Findings and discussion}

Reflecting the wider chronic illness literature (e.g. Dyck, 1995; Crooks, 2010; Smith, 2012), participants in this study were particularly challenged by the unpredictable and therefore liminal nature of life with Ménière's. Life fluctuated between active phases of the condition, when a vertigo attack could occur with little or no warning and leave them unable to move (often accompanied by relentless vomiting and loss of bowel control), to remission phases characterised by minimal vertigo but with lingering tinnitus and hearing loss. These were interspersed with in-between phases where daily activities were still restricted to some extent by the anxiety of symptom onset and a general sense of disorientation and imbalance. The latter could be interpreted as 'anomalous time', where people are neither acutely sick nor completely well (Hannum and Rubinstein, 2016). The most severe and recurrent episodes of vertigo appeared to occur during the first 2-10 years after each participant's first vertigo attack, accompanied and subsequently followed by long-term tinnitus and progressive and permanent hearing loss. For some people, symptoms had also developed in their 
second ear; the 'bilateral' state of the condition. This constituted a much-feared, though not inevitable, transition within the illness trajectory (as detailed by Bell, in press). Four study participants self-identified as bilateral, primarily through experiencing sensations of tinnitus and hearing loss in both ears.

In what follows, we examine how shifts in participants' illness trajectories were intersected by wider familial transitions, and the repercussions of such transitions for their self-concepts, family relationships and 'hoped-for' future trajectories. We focus primarily on the narratives of participants diagnosed with Ménière's for over five years in order to examine how the progression rather than solely the onset of chronic illness can be disruptive, specifically in the context of transitional life stages and shifting relationships linked to early parenthood, familial illness, and early retirement.

\section{Parenthood, fragility and cherished time}

Much of the chronic illness literature demonstrates how 'pain and discomfort provoke a new consciousness of the body, and the contingent and fragile nature of (embodied) existence' (Llewellyn et al., 2014: 49). Few of these studies, however, have examined how this sharpened sense of embodied vulnerability extends to the fragile lives of affected individuals' children, or the implications of shifting illness trajectories on parent-child relationships. On the one hand, this included concerns about the unknown genetics of the condition. As one participant (Maggie) commented about her grown-up children, "they tell us regularly they don't want it, don't want our crap ears!" On the other hand, participants with younger children discussed the adverse impacts of recurrent and intrusive Ménière's symptoms on their ability to fulfil desired parental roles. For example, Becky (a participant in her early thirties) explained how giving birth coincided with highly disorientating experiences of 'robotic' tinnitus in her non-Ménière's ear. Although she had lived with Ménière's in one ear since she was 17 , the fear that her condition was shifting to a bilateral state 
and the implications of this for her new and future role as a parent catalysed a period of intense anxiety.

Becky: "I had what I think would be classed as post-natal anxiety. I wasn't at all depressed but just completely like on a white knuckle ride, thinking 'I'm going to go deaf, I'm going to be a deaf mum, I don't know how to do this. I'm going to live with this awful tinnitus, everyone's going to sound like a robot forever' ... I was like that for about six months, sweating, diarrhoea, lost loads of weight, couldn't sleep, just completely panicked. I was up half the night breastfeeding, just on my own in the bedroom, in the quiet with the tinnitus. And at night, when you've not got much sleep, it really roars ... I think having our daughter and her needing me, breastfeeding her, literally pulled me through that time"

Becky received little medical or psychological support to manage this anxiety, despite approaching her GP, the ENT (Ear Nose and Throat) department and the local Community Mental Health team, and she therefore deeply valued the support and security provided by her husband during this time. Having been together for over a decade, she felt her husband had seen her determination to live a full life despite Ménière's and therefore gave her the time, space and support she needed to adjust to this latest challenge in the illness trajectory.

Becky: "Since having our daughter and the awful anxiety that I had, my husband was very much a rock... We'd just kind of talk about my ear and why I was feeling anxious, and he's got the patience of a saint to go over and over, and to hear me - because the first year of this bilateral tinnitus, I've had to moan a lot and say 'God, this is awful, how can I live like this? I just want to die', and all these awful negative things... I don't say them so much anymore but I'm really glad that he was able to just let me say them, and to not try and change my thoughts, or just, 
allow me to put them out there... I think he's seen my determination to get through it all as well, and probably, hopefully, he's got a bit of respect for that"

Concerns about the impacts of intensifying Ménière's symptoms on the family as a whole were raised by a number of participants, including the fear of detrimental impacts on their children's lives, and the pressure placed upon partners to ensure both financial and family stability. For example, one participant, Emily had impaired hearing in one ear since childhood and had been living with Ménière's in the other ear for about 12 years, experiencing severe and recurrent vertigo attacks throughout much of that period. The debilitating nature of these attacks - coupled with the bilateral hearing impairment - hindered her ability to work or look after the family as she had prior to the onset of the condition, placing significant pressure on her husband (Bob). The loss of these valued family roles, in turn, compounded feelings of depression, guilt and anguish for Emily.

Emily: "Poor old Bob was trying to do everything - look after the girls, look after the house. It was horrendous. How we stayed together, how you [to husband] put up with me I don't know. And how our youngest coped with it all and came out as sane as she is, I don't know! ... I would say it's made her very very very caring because you [to her daughter] are a sort of very caring person and I think it's probably done that, but I think it's also made you worry too much"

The potential for parental illness experiences to promote compassion in children and to foster reciprocity and care for others (provided they are not over-burdened with excessive caregiving responsibility and worry) has been noted in the wider literature. For example, Prilleltensky (2004: 221) highlights the pride felt by parents with physical disabilities as they watch their children grow up to be 'well adjusted, caring and appreciating of human diversity'. Emily and her husband recalled their daughter coming home during her school lunch hour to check on them, and sitting next to Emily during night-time vertigo attacks. Her daughter contributed to interview discussion at times, commenting, 'I mean, I'm still a normal 16-year old (laughs) but I think I did have to grow up quite 
quick, like mentally, but I think it made me and mum quite close, like we're all really close". Appreciating this, Emily explained how special it had been over the last year to be able to enjoy some more 'typical' mother-daughter activities since her vertigo attacks had started to stabilise.

Emily: "I think I've come to the realisation that I've got to enjoy what I've got a little bit, because we're very lucky to be where we are now, after what we've been through. I'm very lucky to have these two [husband and daughter] that have supported me, and I think that mentally you have to focus on that and keep trying to do little bits. I mean, I was desperate to be like 'mother and daughter', because I used to sit in the car and see those mothers and daughters out shopping and doing things that mothers and daughters do together... and it's amazing now because I can go into town and I can walk around... I mean, that to me, is amazing!"

Such findings emphasise how the onset and progression of chronic illness serve to enhance awareness of one's own fragility, but also that of the wider family unit, illustrating how biographical disruptions are entwined with, and therefore affect, the life trajectories of linked others. In the face of such changes, participants emphasised the importance of making the most of positive shared experiences - or as Becky also noted, feeling "grateful for each day of normality... Just very much counting my blessings". This suggests a form of 'cherished time'; time spent maximising the opportunities provided by remission phases to work on relationships and 'build' family in spite of (or, as Emily explained, within the parameters allowed by) the illness trajectory. This could be interpreted as an 'illness gain' in the face of disruption (Richardson et al., 2006), whereby affected individuals perceive changed priorities and personal growth as a result of their experiences, learning to appreciate pleasures they had previously taken for granted prior to illness onset. 
Experiences of chronic illness - and associated biographical disruptions - may also coincide with the chronic or terminal illness trajectories of adult dependants within the family (Lindsay, 2009). Participants noted particular challenges in the face of collisions between their personal illness trajectories and those of ageing parents with increasingly demanding care needs. In these cases, the emotional impact of protracted caring responsibilities served to exacerbate participants' Ménière's symptoms, creating extended periods of 'turbulent' time, where neither the participants nor their adult dependants were able to stabilise symptoms in response to their intersecting illness trajectories. Difficulties were most pronounced amongst participants who were caring for ageing parents with severe cognitive decline, as illustrated in the exchange between Debbie and her husband, Mick, below.

Researcher: Can you think of any phases where the occurrence of other health conditions or life events has made it difficult to cope with the Ménière's?

Debbie: [turns to husband] Can you think of anything?

Mick: Well, your situation now.

Debbie: [pause] I've got my mother living with me, and I care for her. I can't cope anymore.

Mick: She's got Alzheimer's.

Debbie: She's got Alzheimer's. I can't cope anymore. I'm having to put her in a home, so that's making it... [pause]. She's in bed at the moment. But they're trying to sort that out for me because I just can't go on. I don't want to live anymore like I'm living. It's too much stress for me what with - before I could have coped with anything. I can't now [pause]. It's just got too much for me.

Researcher: Aw how long has your mum been living here? 
Debbie: Sixteen years. And I, as I say, I think I could possibly have coped with it longer if I hadn't had this but what with this as well, trying to cope with this and not knowing when it's coming and that. It makes it so difficult.

This extract highlights the extent of the challenges of managing one's own unpredictable symptoms alongside those of an ageing parent. Debbie repeatedly states that she cannot cope anymore. She had managed the caregiving role alongside a full time job for many years until her Ménière's symptoms grew significantly worse (approximately seven years prior to the interview) and her mother developed severe Alzheimer's (three years prior to the interview). The guilt of relinquishing that caregiving role was noted by another participant, Caroline, who was in her fifties, with a difficult illness history herself, including asthma, eczema, glandular fever, migraines, fibroids and urticaria. Reflecting the findings of Lindsay (2009), Caroline's prior experience with illness did not ease the impact of the Ménière's progression due to its unpredictable, shifting characteristics. Ménière's left her unable to work and her husband became the sole earner for the household. However, Caroline was also engaged in full time caregiving for her mother who had lived with them for many years after Caroline's father passed away, eventually developing Alzheimer's.

Caroline: "I used to manage to cook her something and then I had to put it on the floor, and kneel, and push it to her room. That's how I fed my mum... I felt that ill I couldn't stand up... it was wearing me out and I actually asked God to take me away... honestly, it was an awful time... I think I got that low and that's why I got pneumonia and pleurisy and all that sort of stuff, because it dragged me down"

Around the time that Caroline's health was deteriorating, her husband was forced to relocate for work. At this point, Caroline's symptoms reached a threshold where she felt stretched to 'breaking point' (Read and Wuest, 2007), no longer able to prioritise her mother's illness over her own. She and her husband found a care home for her mother in order to minimise the upheaval whilst they looked for a new place to live but she had only been in the home for a few weeks when she passed 
away. The combined guilt of not being with her mother at the time and the deep sense of loss following the bereavement contributed to experiences of biographical 'fracture', encouraging Caroline to seek counselling support.

Caroline: "I do have counselling but it's not for my Ménière's, although it does come up... but I see a counsellor because I lost my mum in 2011 and I really miss her (pause). I think, she took over a lot of my life, and then when I didn't have her, I just feel I was lost, a bit lost... and I felt so bad because when she was living with us, we used to chat and everything, and she'd say to me 'When my time's up, I don't want to be on my own' and l'd say 'You're not going to be on your own, I'm going to be here', and then I wasn't with her... I shouldn't have promised her, but you do, don't you? ... So the following year, 2012, I don't think I was very good at all. Grief is an awful thing, you don't know what you're doing, who you are, what's happening"

The counselling sessions enabled Caroline to work through both her grief and the sense of guilt and turmoil regarding the decision to place her mother in formal care. The emotional turbulence experienced by caregivers during the transition of their loved one from home to institutional care is well documented in the Alzheimer's literature (as reviewed by Afram et al., 2015). For the family caregiver, the transition may be eased by seeing their relative receive better institutional care than they could offer at home, by maintaining a positive but less intensive role in the caregiving process through regular day visits, and via pursuing new interests to stay busy in the absence of the previous caregiving role (Read and Wuest, 2007). Such comforts were, however, elusive for Caroline due to the combined experience of losing her mother so soon after moving her into formal care, and the concurrent deterioration of her own health.

Over time, Caroline learnt to take comfort from the many years that she had dedicated to her mother's care; "I was proud of what I'd done for her... and I know that she, she knew what I'd 
done", and began to identify and understand wider factors contributing to her grief and loss. These coalesced around the compromised sense of self resulting from her inability to perform previously cherished caring roles in her everyday life and her increasing dependence on others in managing Ménière's.

Caroline: "I've always been a bit of a carer. I brought my sister up as there's 13 years between me and her, so I was like the mum to her, you know (pause)... and then of course you go and have your own children and you're caring for them, and then I cared for my mum, and I cared for my dad before he passed away. I think I've always been a carer-type person and then when somebody, when you think'I need a bit of care at the minute', I don't like it. I'd rather be on the other side".

The colliding transitions experienced by Caroline's husband (relocating for work), her mother (with worsening Alzheimer's symptoms) and Caroline herself (experiencing multiple acute and chronic health conditions) contributed to a significant biographical disruption at the end of 2011, with longlasting repercussions for Caroline's sense of self. The deep and debilitating sense of 'turbulent time' generated by such cycles of mutually reinforcing instability, are rarely examined within the biographical disruption literature. Yet our findings illustrate the damaging nature of such cycles for caregiving individuals who are negotiating personal chronic and familial terminal illnesses. In negotiating the multiple and concurrent challenges unfolding in their family life, participants' physical and emotional health can be severely compromised, hindering efforts to engage in either self-care or care of their loved ones.

Retirement, spousal tensions and anomalous time

A further theme emerging through our analysis was the way in which liminal or 'anomalous' time began to pervade the lives of participants who had retired (or were undergoing retirement) as a 
direct result of deteriorating Ménière's symptoms. Anomalous time was characterised by both ambiguity and uncertainty (Cayless et al., 2010; Hannum and Rubinstein, 2016), often catalysing new spousal tensions as it spilled over to the lives of participants' partners.

Changes in individual identities and social roles associated with retirement render it an emotional, often challenging life transition even without the added complications of chronic illness (Milligan et al., 2005). Participant experiences of retirement varied according to the role played by Ménière's in shaping the retirement decision, as well as the career stage and retirement preferences of their partners. Participants who had been passionate about their career and unable to see it through to a perceived 'natural' end point as a result of Ménière's described the difficulties in finding fulfilling ways to adapt to retired life. The fear of letting people down, in particular, hindered efforts to re-build their lives and pursue new meaningful activities. This, in turn, created high levels of frustration and a sense of being trapped in prolonged phases of anomalous time. One participant (Dawn) explained the guilt she felt for causing spousal tension whilst she tried to adapt to this form of early retirement.

Dawn: "Because I get frustrated that I can't do what I did before, or I'm not doing what I did before, or I'm not fully fulfilled, I get ratty with my husband, whereas I never used to before. That's very big of me to say that [laughs], because, because it's quite hard to say isn't it, really ... I don't think I do it anymore now because I think I'm doing more and I'm getting out there more, but it was like, you know, I've got no life, there's nothing'... not wanting to over-commit to anything where I'm very much relied upon... I don't want to put myself back in that situation... I couldn't bear not being reliable"

The increased reliance on partners constituted a particularly difficult adjustment for several participants. For example, Angus, a participant in his early 60 s who had been forced to give up work when his symptoms went bilateral, commented, "So I'm now supported by my wife, which doesn't go 
down well - with me, not with her. It doesn't feel right that I'm not earning anything". Frustrations were exacerbated in such situations when participants were negotiating changes in both their selfconcept (through the loss of previously valued career-oriented roles) and the marital relationship (e.g. spending more time with each other without the distraction of work or children). This is apparent in Yvonne's extract below. For many years, Yvonne held a senior role in her profession and a pivotal role within what she describes as her 'matriarchal' family. Being forced to retire early as a result of worsening Ménière's symptoms disrupted this life, created an embodied dependency on her husband who was already comfortably settled into a retirement rhythm.

Yvonne: "You're suddenly back as a couple that you were before you had your children. So that takes quite an adjustment as well because you've moved along in parallel motion, I think, for a long period of time. We do have some likes and dislikes that are similar which you would expect, but we do have quite a lot that doesn't tie up ... and with the Ménière's I became very reliant on him which I hadn't been. I'm very much my own person [laughs] and do my own thing, and in fact I call it a matriarch family because I am the cog and, you know, he sort of revolves around me. Whereas suddenly I was having to rely on him to do things, which was quite hard to handle... I became physically needing him"

Whilst Dawn's and Yvonne's partners were already retired, other participants described the challenges of being forced to retire when their partners were still at work. Not only did this alter previous relationship dynamics (for example, as their partners became the sole household earner), it also created a sense of pressure on their partners to retire, even when they did not feel ready to do so. As illustrated in the extract from Magda's interview below, tensions emerged when partners' own needs, career trajectories and associated self-concepts were overlooked. Magda had married participant, John (who also had severe diverticular disease alongside unilateral Ménière's, and 
minimal hearing capacity in his non-Ménière's ear as a result of a childhood accident), ten years earlier, which was a second marriage for each of them.

Magda: "We can't do as much as we had hoped we would. So l've gone back to work, which is just a life-saver. It's, it's brilliant... it made me feel guilty going to work because I knew he didn't like it [pause]. But I, I had this feeling that as it is now, I've had my babies and they're grown up and they're mainly taken care of, and I, I [sighs], there is no more purpose to me. And so rather than sitting at home and waiting to die, and maybe read some books (which I feel doesn't contribute to anyone else), I just get out and get busy and forget about that thing that's underlying my view of life. So that, that solved my problem, it didn't help his. Some people say, you know, 'you married somebody at the age you did, they expect companionship'. Hmmm [sighs]"

These extracts illustrate the challenges of negotiating retirement when it is perceived to be 'off time' (Laranjeira et al., 2015) with an anticipated or hoped-for shared life trajectory, often serving to intensify shared experiences of biographical disruption. Worsening illness trajectories undermined the 'social clock' of participants (Faircloth et al., 2004), rendering them 'out of sync' with their partners. Partners who had already retired were largely supportive and willing to accommodate the 'dynamic normality' (Locock et al., 2009) of life with Ménière's into their entwined retirement trajectory. However, others were reluctant to retire whilst opportunities to replace their careeroriented identities with alternative but equally valued social roles risked being constrained by their partner's illness progression. This reflects a reluctance to be pulled more fully into their partner's world of 'anomalous time'. In the example above, Magda is searching for a pursuit that could bring a sense of purpose to her retirement, but is not prepared to embrace the transition from 'lover to mother' of her partner at this stage of their marriage or retirement (Dow and Meyer, 2010: 653). These findings extend existing literature in the field by highlighting how experiences of biographical 
disruption can be magnified and compounded by spousal tensions and shifts in relationship dynamics occurring as chronic illness progression intersects with feelings of liminality catalysed by premature retirement.

\section{Concluding reflections}

In this paper, we have examined how the intersections of personal illness trajectories and shared familial life transitions - specifically parenthood, caregiving, and early retirement - can hinder illness adjustment and magnify shared experiences of biographical disruption amongst individuals living with longstanding Ménière's disease; a progressive, chronic vestibular disorder. In doing so, we respond to calls to analyse people's experiences of chronic illness within the context of shifting family relationships and interconnected life transitions (Gregory, 2005; Monaghan and Gabe, 2015). We also extend Bury's (1992) concept of 'biographical disruption' to understand the experiences of those undergoing later-stage shifts in their illness trajectory rather than focusing solely on those facing illness onset (Larsson and Grassman, 2012).

Our findings support previous work suggesting that chronic illnesses and their progression can be unexpected, feared and anticipated at the same time (Reeve et al., 2010; Larsson and Grassman, 2012). This was particularly so when: (a) critical illness events or turning points (e.g. shifting to significantly more frequent, severe and/or bilateral Ménière's symptoms) coincided with wider life transitions; (b) the illness trajectory was deemed more unpredictable than challenges encountered earlier in the life course (Lindsay, 2009); and (c) desired/pre-illness identities allowed few concessions to be made to protect oneself in the face of the most debilitating symptoms (Gregory, 2005). Whilst some participants were able to preserve aspects of ontological security through the stability provided by close social relationships (e.g. Becky, Emily), others described the spousal tensions catalysed by their loss of independence (as noted by Yvonne, Angus and Magda) and the destabilising effects of their own familial caregiving responsibilities (e.g. Debbie, Caroline). 
When considering the impact of Ménière's in the context of participants' wider lives, it was clear that many felt the illness trajectory was 'off time' in relation to their expected life course trajectories. In this way, the timing of the condition was experienced as disruptive, undermining their efforts to fulfil desired and/or expected social roles for their life stage or to 'conform' to sociocultural life course norms (Laranjeira et al., 2015). For example, Becky was not ready to be a 'deaf' mum, Caroline felt prematurely 'pulled away' from the care of her ageing mother with Alzheimer's, Angus and Yvonne were reluctant to relinquish valued social roles at work and home, and Magda felt it was too soon into her second marriage to retire and risk a potential shift from 'lover to mother' of her husband. Participant accounts reflected fluctuating experiences of 'cherished' time (valuing periods of remission when desired activities and social roles were less encumbered by illness), 'anomalous' time (phases of uncertainty and ambiguity when symptoms or deep-seated fear of symptoms hindered the performance of previously taken-for-granted routines and identities), and 'turbulent' time (where physical and emotional health were deeply undermined as a result of collisions between multiple and concurrent life challenges, illness-related and otherwise).

These findings encourage critical reflection on the identity-limiting and self-damaging nature of oppressive social norms and entrenched cultural life course constructions that fail to recognise life's dynamism and alternative ways of 'living well'. It is often only in later life that we 'expect' to encounter vulnerability and fragility, such that episodes of severe acute or chronic illness experienced earlier in the life course (by ourselves or our loved ones) are interpreted as 'off time' and therefore deemed disruptive to desired or anticipated life trajectories. The findings of this study suggest, however, that health and wellbeing exist as a continuum that we oscillate along as our roles, responsibilities, priorities and capabilities shift with different life events and transitions. At times, we fall further towards ill health (physically, socially and/or mentally). This might be a temporary shift, with medication, social support, self-care and the passing of time bringing us back (or close) to our previous state. Alternatively, it may be a more permanent shift - as with many chronic illnesses - where we are forced to adjust to an alternative way of being, doing, feeling and 
thinking in the world. As seen in this paper, adapting to this 'shifting normality of doing things differently' (Davidson and Henderson, 2010: 464) takes substantial effort, involving invisible and embodied practical, emotional and social work, both for the individuals concerned and their wider support network (Smith, 2003).

Rather than conceptualising the onset and progression of chronic illness as a one-off biographical 'disruption' that steers us off an 'illusory' linear or predictable life trajectory (ŠikićMićanović, 2013), we suggest it could usefully be reframed as one of many 'biographical oscillations' encountered in the life course that re-route us between continually shifting, often 'messy' and unanticipated life trajectories. These may diverge from and challenge existing life course 'norms' and expectations, thereby attuning us to the fragile nature of the culturally anticipated trajectory we originally embarked on. As we negotiate these alternative life maps, we learn to appreciate moments of contented pause, and become more familiar with the anxieties that threaten to overcome us when faced with another diversion. The challenge lies in identifying those most at risk of being pushed into 'turbulent' or 'anomalous' time during life's oscillations and to support (practically, socially and psychologically) their efforts to find alternative sources of stability and maximise experiences of 'cherished' time with those around them. Future work could explore this further using longitudinal mixed method study designs with larger samples to examine shifting illness perceptions and experiences at different phases of the condition and life stages, providing greater awareness of the more elaborate and wide-ranging 'biographical maps' (Leveälahti et al., 2007) that life can follow.

\section{Acknowledgements}

Many thanks go to all the study participants for sharing their experiences; Mr. David Whinney (Ear Nose and Throat Consultant at Royal Cornwall Hospital Treliske), Clinical Project Advisor; the 
Ménière's Society for funding the study; and PenCLAHRC (the National Institute for Health Research Collaboration for Leadership in Applied Health Research and Care South West Peninsula) for providing follow-on funding. The views expressed are those of the authors and not necessarily those of the NHS, the NIHR, the Department of Health or the Ménière's Society. We would also like to thank the three anonymous reviewers for their valuable feedback on an earlier draft of this paper.

\section{References}

Afram, B., Verbeek, H., Bleijlevens, M.H.C., \& Hamers, J.P.H. (2015) Needs of informal caregivers during transition from home towards institutional care in dementia: a systematic review of qualitative studies. International Psychogeriatrics, 27(6), 891-902.

Bell, S.L. (In press) The role of fluctuating soundscapes in shaping the emotional geographies of individuals living with Ménière's disease. Social \& Cultural Geography.

Bourdieu, P. (2000) The Biographical Illusion. In Du Gay, P., Evans, J. and Redman, P. (eds) Identity. A Reader. London: Sage Publications, pp. 297-303.

Bury, M. (1982) Chronic illness as biographical disruption. Sociology of Health \& Illness, 4, 167-182.

Cayless, S., Forbat, L., Illingworth, N., Hubbard, G., \& Kearney, N. (2010) Men with prostate cancer over the first year of illness: their experiences as biographical disruption. Support Care Cancer, 18, 11-19.

Charmaz, K. (1995) The Body, Identity, and Self: Adapting to Impairment. The Sociological Quarterly, $36(4), 657-680$. 
Charmaz, K. (1983) Loss of self: a fundamental form of suffering in the chronically ill. Sociology of Health \& IIIness, 5, 167-195.

Croft, S. (2012) Constructing Ontological Security: The Insecuritization of Britain's Muslims.

Contemporary Security Policy, 33(2), 219-235.

Crooks, V.A. (2010) Women's changing experiences of home and life inside it after becoming chronically ill. In Choinard, V., Hall, E., \& Wilton, R. (eds) Towards Enabling Geographies: 'Disabled' Bodies and Minds in Society and Space. Surrey: Ashgate Publishing Ltd, pp. 45-62.

Danermark, B.D., \& Möller, K. (2008) Deafblindness, ontological security, and social recognition. International Journal of Audiology, 47(S2), S119-S123.

Davidson, J., \& Henderson, V.L. (2010) 'Travel in parallel with us for a while': sensory geographies of autism'. The Canadian Geographer, 54(4), 462-475.

Denzin, N. (1989) Interpretive Biography. Qualitative Research Methods Series 17, A Sage University Paper. London: Sage Publications.

Depkat, V. (2014) The challenges of biography: European-American Reflections. Bulletin of the GHI, $55,39-48$.

Dow, B., \& Meyer, C. (2010) Caring and retirement: crossroads and consequences. International Journal of Health Services, 40(4), 645-665.

Dyck, I. (1995) Hidden geographies: the changing lifeworlds of women with multiple sclerosis. Social Science and Medicine, 40(3), 307-320.

Faircloth, C.A., Boylstein, C., Rittman, M., Young, M.E., \& Gubrium, J. (2004) Sudden illness and biographical flow in narratives of stroke recovery. Sociology of Health \& IIIness, 26(2), 242-261.

Frank, A. (1995) The Wounded Storyteller. Chicago: University of Chicago Press. 
Giddens, A. (1991) Modernity and Self-Identity. Cambridge: Polity.

Grassman, E.J., Holme, L., Larsson, A.T., \& Whitaker, A. (2012) A long life with a particular signature: life course and aging for people with disabilities. Journal of Gerontological Social Work, 55(2), 95111.

Gregory, S. (2005) Living with chronic illness in the family setting. Sociology of Health \& IIIness, 27(3), 372-392.

Grenier, A. (2012) Transitions and the Lifecourse: Challenging the Constructions of 'Growing Old'. Bristol: The Policy Press.

Hannum, S.M., \& Rubinstein, R.L. (2016) The meaningfulness of time; Narratives of cancer among chronically ill older adults. Journal of Aging Studies, 36, 17-25.

Kirby, S.E., \& Yardley, L. (2008) Understanding psychological distress in Ménière's disease: A systematic review. Psychology, Health and Medicine, 13, 257-273.

Kirby, S.E., \& Yardley, L. (2012) Physical and Psychological Triggers for Attacks in Ménière's Disease: The Patient Perspective. Psychotherapy and Psychosomatics, 81, 396-398.

Laranjeira, C.A., Leão, P.P., \& Leal, I. (2015) Temporal experience among women gynaecological cancer survivors: a lifeworld perspective. Journal of Women and Social Work, 30(2), 170-186.

Larsson, A.T., \& Grassman, E.J. (2012) Bodily changes among people living with physical impairments and chronic illnesses: biographical disruption or normal illness? Sociology of Health \& Illness, 34(8), p1156-1169.

Leveälahti, H., Tishelman, C., \& Öhlén, J. (2007) Framing the onset of lung cancer biographically: Narratives of continuity and disruption. Psyco-Oncology, 16, 466-473. 
Lindsay, S. (2009) Prioritising Illness: lessons in Self-managing Multiple Chronic Diseases. Canadian Journal of Sociology, 34(4), 983-1002.

Llewellyn, H., Low, J., Smith, G., Hopkins, K., Burns, A., \& Jones, L. (2014) Narratives of continuity among older people with late stage chronic kidney disease who decline dialysis. Social Science \& Medicine, 114, 49-56.

Locock, L., Ziebland, S., \& Dumelow, C. (2009) Biographical disruption, abruption and repair in the context of Motor Neurone Disease. Sociology of Health \& IIIness, 31(7), 1043-1058.

Milligan, C., Bingley, A., \& Gatrell, A. (2005) 'Healing and Feeling': The place of emotions in later life. In: Davidson, J., Bondi, L., \& Smith, M. (eds) Emotional Geographies. Surrey: Ashgate Publishing, pp. $49-62$

Monaghan, L.F., \& Gabe, J. (2015) Chronic illness as biographical contingency? Young people's experiences of asthma. Sociology of Health \& IIIness, 37(8), 1236-1253.

Nettleton, S., Watt, I., O'Malley, L., \& Duffey, P. (2005) Understanding the narratives of people who live with medically unexplained illness. Patient Education and Counseling, 56, 205-210.

Patton, M. (1990) Qualitative evaluation and research methods. Beverly Hills: SAGE, pp. 169-186.

Phoenix, C., Smith, B., \& Sparkes, A. (2010) Narrative analysis in aging studies: a typology for consideration. Journal of Aging Studies, 24, 1-11.

Phoenix, C., Tyrrell, J., \& Bell, S.L. (2015) Living with Ménière's disease: Understanding patient experiences of mental health and wellbeing in everyday life. Final Report to the Ménière's Society, University of Exeter Medical School, European Centre for Environment and Human Health, Truro, UK, October.

Prilleltensky, O. (2004) My child is not my carer: mothers with physical disabilities and the well-being of children. Disability \& Society, 19(3), 209-223. 
Read, T., \& Wuest, J. (2007) Daughters caring for dying parents: a process of relinquishing. Qualitative Health Research, 17(7), 932-944.

Reeve, J., Lloyd-Williams, M., Payne, S., \& Dowrick, C. (2010) Revisiting biographical disruption: Exploring individual embodied illness experience in people with terminal cancer. Health, 14(2), 178195.

Richardson, J.C., Nio Ong, B., \& Sim, J. (2006) Is chronic widespread pain biographically disruptive? Social Science \& Medicine, 63, 1573-1585.

Riessman, C.K. (2008) Narrative Methods for the Human Sciences. London: SAGE Publications.

Roberts, K., \& Clarke, C. (2009) Future disorientation following gynaecological cancer: Women's conceptualisation of risk after a life threatening illness. Health, Risk \& Society, 11(4), 353-366.

Sanderson, T., Calnan, M., Morris, M., Richards, P., \& Hewlett, S. (2011) Shifting normalities: interactions of changing conceptions of a normal life and the normalisation of symptoms in rheumatoid arthritis. Sociology of Health \& IIIness, 33(4), 618-633.

Sinding, C., \& Wiernikowski, J. (2008) Disrupted foreclosed: older women's cancer narratives. Health: An Interdisciplinary Journal for the Social Study of Health, IIIness and Medicine, 12(3), 389-411.

Šikić-Mićanović, L. (2013) Using biographical research to understand experiences of crisis among homeless people in Croatia. Etnološka tribina, 36(43), 99-109.

Smith, D. (2003) Making sense of what people do: a sociological perspective. Journal of Occupational Science, 10(1), 61-64.

Smith, N. (2012) Embodying brainstorms: the experiential geographies of living with epilepsy. Social and Cultural Geography, 13, 339-359. 
Tracy, S. (2010) Qualitative Quality: Eight 'Big Tent' criteria for excellent qualitative research. Qualitative Inquiry, 16, 837-850.

Tyrrell, J., White, M., Barrett, G., Ronan, N., Phoenix, C., Whinney, D., \& Osborne, N. (2015) Mental Health and Subjective Wellbeing of individuals with Ménière's: Cross Sectional Analysis in the UK Biobank.

Otology \& Neurotology, 36, 854-861.

Williams, S.J. (2000) Chronic illness as biographical disruption or biographical disruption as chronic illness? Reflections on a core concept. Sociology of Health \& Illness, 22(1), 40-67.

Yardley, L., Dibb, B., \& Osborne, G. (2003) Factors associated with quality of life in Ménière's disease. Clinical Otolaryngology, 28, 436-441. 
Table 1. Sample composition

\begin{tabular}{|c|c|c|c|c|c|}
\hline Pseudonym & $\begin{array}{c}\text { Age bracket } \\
\text { (yrs) }\end{array}$ & $\begin{array}{l}\text { Ménière's } \\
\text { duration }\end{array}$ & $\begin{array}{c}\text { Unilateral/ } \\
\text { bilateral } \\
\text { symptoms? }\end{array}$ & $\begin{array}{l}\text { Employment } \\
\text { status }\end{array}$ & $\begin{array}{l}\text { Presence of } \\
\text { others during } \\
\text { interview? }\end{array}$ \\
\hline \multicolumn{6}{|c|}{ Participants with Ménière's } \\
\hline Maggie & $51-60$ & $<5 y r s$ & Unilateral & Full time & - \\
\hline Nicola & $31-40$ & $<5 y r s$ & Unilateral & Full time & - \\
\hline Jane & $61-70$ & $<5 y r s$ & Unilateral & Retired & - \\
\hline Louisa & $51-60$ & $<5 y r s$ & Unilateral & Full time & - \\
\hline Susan & $61-70$ & $<5 y r s$ & Unilateral & Retired & - \\
\hline Melissa & $31-40$ & $<5 y r s$ & Unilateral & Full time & - \\
\hline Tom & $41-50$ & $<5 y r s$ & Unilateral & Full time & - \\
\hline Debbie & $61-70$ & $>5 y r s$ & Unilateral & Non-working & Husband (Mick) \\
\hline Becky & $31-40$ & $>5 y r s$ & Bilateral & Non-working & Daughter (toddler) \\
\hline Dawn & $51-60$ & $>5 y r s$ & Unilateral & Early retirement & - \\
\hline Angus & $61-70$ & $>5 y r s$ & Bilateral & Early retirement & - \\
\hline Chloe & $51-60$ & $>5 y r s$ & Unilateral & Part time & - \\
\hline Yvonne & $61-70$ & $>5 y r s$ & Unilateral & Early retirement & - \\
\hline Caroline & $51-60$ & $>5 y r s$ & $\begin{array}{c}\text { Shifting to } \\
\text { bilateral }\end{array}$ & Non-working & $\begin{array}{c}\text { Husband for last } \\
\text { half hour }\end{array}$ \\
\hline Jennie & $41-50$ & $>5 y r s$ & Bilateral & Part time & $\begin{array}{l}\text { Teenage daughter } \\
\text { for last half hour }\end{array}$ \\
\hline Emily & $51-60$ & $>5 y r s$ & Unilateral & Non-working & $\begin{array}{c}\text { Husband, teenage } \\
\text { daughter }\end{array}$ \\
\hline Richard & $61-70$ & $>5 y r s$ & Unilateral & Retired & - \\
\hline Elaine & $71-80$ & $>5 y r s$ & Unilateral & Retired & Husband \\
\hline John & $71-80$ & $>5 y r s$ & Unilateral & Early retirement & $\begin{array}{c}\text { Grandson (on and } \\
\text { off through } \\
\text { interview) }\end{array}$ \\
\hline Emma & $51-60$ & $>5 y r s$ & Unilateral & Self employed & - \\
\hline \multicolumn{6}{|c|}{ Participants supporting someone with Ménière's } \\
\hline $\begin{array}{c}\text { Karen } \\
\text { (Angus' wife) }\end{array}$ & $62-70$ & $\mathrm{~N} / \mathrm{A}$ & N/A & Full time & - \\
\hline $\begin{array}{c}\text { David } \\
\text { (Susan's husband) }\end{array}$ & $61-70$ & N/A & N/A & Self employed & - \\
\hline $\begin{array}{c}\text { Magda } \\
\text { (John's wife) }\end{array}$ & $61-70$ & N/A & N/A & Part time & - \\
\hline $\begin{array}{c}\text { Matt } \\
\text { (Maggie's husband) }\end{array}$ & $61-70$ & N/A & N/A & Self employed & - \\
\hline $\begin{array}{c}\text { Sandy } \\
\text { (Dawn's husband) }\end{array}$ & $61-70$ & N/A & N/A & Retired & $\begin{array}{l}\text { Wife (Dawn) for } \\
\text { last half hour }\end{array}$ \\
\hline $\begin{array}{c}\text { Mick } \\
\text { (Debbie's husband) }\end{array}$ & $71-80$ & N/A & N/A & Retired & Wife (Debbie) \\
\hline $\begin{array}{c}\text { Toby } \\
\text { (Jennie's husband) }\end{array}$ & $51-60$ & N/A & N/A & Full time & - \\
\hline $\begin{array}{c}\text { Tessa } \\
\text { (Tom's wife) }\end{array}$ & $41-50$ & N/A & N/A & Part time & Daughter (toddler) \\
\hline
\end{tabular}

